I agree with Dr Devonald's comment that most GPs will only fit Mirenas. In my opinion, this is contrary to patient choice and good practice. In the area where I work, women are directly asking for a non-hormonal LARC, or after discussions find irregular bleeding patterns or amenorrhoea with Mirena unacceptable. Also, an IUD may be needed for emergency contraception purposes. Therefore, I believe that the copper IUD is a very useful method in good hands and there is enough evidence around to prove this.

In the light of the above comments, I would therefore argue that there is no need to consider changing the criteria for the Letter of Competence in Intrauterine Techniques (LoC IUT) training. However, more importantly, our efforts should focus on improving timely access to high-quality training for LoC IUT and Letter of Competence in Subdermal Contraceptive Implant Techniques (LoC SDI). I have been made aware by current trainees that there are some real issues with arranging suitable practical training sessions. There can be a wait for up to a year in some areas for training. Some GP registrars are no longer planning to undertake LoCs as they feel that there is a lot to do during their training year and they cannot spare the time, particularly if the training clinic is located miles away. Some of the trainees are also unable to obtain study leave or find locums if they wish to undertake LoCs. This is more worrying for the speciality as a whole and obviously limits patients' choice in the long term. I wonder, therefore, whether there is any possibility of including DFSRH (formerly DFFP) and LoC training as it relates to IUDs/implants as a core skill during the obstetrics and gynaecology placement?

Farzana Siddiqui, FRCOG, MFFP Consultant in Contraception and Sexual Health, Oldham Primary Care Trust, Failsworth

Primary Care Centre, Oldham, UK.

E-mail:farzana.siddiqui@nhs.net

Reference

Devonald B. Training for the LoC IUT (Letter). J Fam Plann Reprod Health Care 2007; 33: 288-289.

\section{Missed opportunities in}

\section{discussing LARC}

We conducted a study on the feasibility of selfcompleted history questionnaires in a central London community contraceptive clinic in October 2006. Participants were established users of combined hormonal contraception (CHC, which includes the pill and the patch) requesting repeat supplies. ${ }^{1}$ Along with questions on personal and family history to identify risk factors, we included a question: "Would you like to discuss other methods of contraception such as long-acting methods which you do not have to remember to take each day?" Twenty-one percent (68/328) of women replied 'Yes' to this question. This is an important finding, considering the fact that these women were already well established on their $\mathrm{CHC}$.

Given this response, we suggest that when a woman comes for repeat supplies of her $\mathrm{CHC}$, it should be taken as an opportunity to discuss longacting reversible contraception (LARC) methods. Choice of contraception is essential to meet diverse user needs, and preferences may change with the user's stage in life. Only by offering choice will the maximum number of women be protected and will the uptake of LARC increase. If health professionals make assumptions that a woman's current method of contraception is the best and most acceptable to her, they could be missing opportunities for discussing other methods.

National Institute for Health and Clinical Excellence (NICE) guidance recommends that al women requiring contraception should be given information about, and offered a choice of, all methods, including LARC. ${ }^{2}$ Little is known about the extent to which women requesting contraception are actually offered these methods In general practice the availability of LARC methods is often limited, which is also likely to affect uptake. ${ }^{3}$

LARC offers definite cost benefits to health services, with all methods being more costeffective than the combined oral contraceptive pill even at 1 year of use. ${ }^{2}$ In addition, these methods offer non-contraceptive health benefits, such as the levonorgestrel intrauterine system providing treatment for menorrhagia. ${ }^{2}$

Non-use of contraception places a far heavier financial burden on society and public funds. ${ }^{4}$ In the UK, an estimated $50 \%$ of pregnancies are unplanned and approximately one-fifth of conceptions end in legal abortions. ${ }^{3}$ An increased uptake of LARC could help to reduce unintended pregnancy.

We support the view that improving access to the full range of contraceptive methods and increasing nationally accredited training for all contraception providers is required. ${ }^{3}$ The potential benefits of LARC methods over CHC can actually be realised if this is applied as an auditable standard for all clinicians involved in contraceptive care.

Jagruti S Doshi, MRCOG, DFFP

Subspecialty Trainee in Sexual and

Reproductive Healthcare, Margaret Pyke

Centre, London, UK.

E-mail: jsdoshi@doctors.org.uk

Rebecca S French, MSc

Senior Research Fellow, Centre for Sexual Health and HIV Research, Department of Primary Care and Population Sciences, Margaret Pyke Centre, London, UK

Christopher L Wilkinson, MBBS, FFFP Consultant, Margaret Pyke Centre and Mortimer Market Centre, London, UK

References

Doshi J, French RS, Evans H, Wilkinson C. Feasibility of a self-completed history questionnaire in women requesting repeat combined hormonal contraception. J Fam Plann Reprod Health Care 2008: 34: 51-54.

National Institute for Health and Clinical Excellence NICE). Long-acting Reversible Contraception (Clinical Guideline 30). London, UK: NICE, 2005. Kishen M, Belfield T. Contraception in crisis. J Fam Plann Reprod Health Care 2006; 32: 211-212.

Sonnerberg FA, Burkman RF, Hagerty CG, Speroff L, Speroff T. Costs and net health effects of contraceptive methods. Contraception 2004; 69: 447-459.

\title{
FACULTY AWARDS
}

The Faculty of Sexual and Reproductive Healthcare has available a number of annual awards for which applications are invited from Faculty members and non-members as listed below. Details of the individual awards, together with an application form and/or guidelines on how to apply and any eligibility criteria, may be found on the Faculty website at www.fsrh.org.

\section{Margaret Jackson Prize Essay}

Award: Three prizes awarded annually for the best essays on a topic related to contraceptive and sexual health care. The first prize is $£ 300$, with $£ 100$ each for the two runners-up.

Eligibility: Individuals (undergraduate medical students)

Closing date: 24 March annually

\section{The David Bromham Annual Memorial Award}

Award: Prize awarded for a piece of work which through inspiration, innovation or energy has furthered the practice of sexual and reproductive health care in any way and any setting.

Eligibility: Individuals (Faculty members) or teams

Closing date: 7 April annually

\section{International Travelling Scholarship of the Faculty}

Award: Scholarship up to the value of $£ 2000$ to fund travel abroad to visit international colleagues, services, research or educational establishments to learn about some aspect of sexual or reproductive health care.

Eligibility: Individuals (Faculty members)

Closing date: 7 April annually

The 4-0-8 Sheffield Fund

Award: Approximately $£ 1000$ will be allocated every 3 months, either as a single award or divided between the successful applicants, for the purpose of funding training for health care professionals who have limited funding for attending training meetings.

Eligibility: Individuals (Faculty members/non-members)

Closing date: See website for details 